\title{
SCIENTIFIC CO-OPERATION WITHIN THE BRITISH COMMONWEALTH*
}

\author{
By H.R.H. THE DUKE OF EDINBURGH, K.G., K.T., F.R.S.
}

W E often hear about the invisible ties of friendship and trust which bind together the mem. bers of the Commonwealth. We do not hear quite so much about the practical advantages of membership or the amount of quiet unspectacular work which is going on to the mutual benefit of the Commonwealth as a whole. I must admit that it came as quite a surprise to me to discover the amount of useful co-operation in science which is going on within the Commonwealth to-day. I was also delighted to find that this co-operation has been active for quite a long time. It is always the same, and I am sure many have also noticed that there is no better way of finding out about a subject than having to speak about it.

\section{Conferences}

One of the first things I discovered was that this address, the subject of which you chose for me, has come at a most appropriate moment because the very first formal step in scientific co-operation was taken exactly fifty years ago. In the year 1909 the Entomological Research Committee for Tropical Africa was formed with headquarters at the British Museum (Natural History), London. The funds came from the African Colonies and the United Kingdom, and it made the first systematic collection and study of insects injurious to men, animals and crops in East and West Africa.

Although this was a very modest venture-the annual budget only amounted to $£ 2,000$-yet it was the start of great things.

The venture was discussed at the Imperial Conference of 1911, and in 1913 it became the Imperial Bureau of Entomology, with two main functions : (1) "the identification of all injurious insects sent in by officers attached to departments of Public Health in countries in the Empire" ; (2) "to issue a monthly periodical giving summaries of all current literature both British and foreign, dealing with noxious insects, whether agricultural pests or disease carriers". In the same year it published its first journal of abstracts.

Next, the Imperial War Conference of 1918 established the Imperial Bureaux (now the Commonwealth Institute) of Mycology at Kew, and it was the Imperial Agricultural Research Conference of 1927 that set up the first Commonwealth Agricultural Bureaux.

In 1933 the Imperial Committee on Economic Consultation and Co-operation met, and one of its decisions was that there should be a seientific conference every five years which, among other things, was to review the working of the Commonwealth Agricultural Bureaux.

It is therefore plain that this subject of Commonwealth co-operation in science has been given serious consideration for a good many years by many hardheaded and practical people. I also want to make it clear that throughout the story the endeavour has been to benefit the Commonwealth as a whole and not the particular interests of any one country.

* Substance of an Address delivered at the Annual Meeting of the Pakistan Association for the Advancement of Science in Karachi on February 7.
Therefore, to resume the story. The first Commonwealth Scientific Conference and First Review Conference of the Commonwealth Agricultural Bureaux was held in London in 1936, and, as a result, two furthor Bureaux were added. Since then, there have been review conferences in 1946, 1950 and 1955 . These concerned themselves mostly with finance and administration, but the last one recommended that the National Institute of Agricultural Engineering should compile and issue abstracts for Commonwealth use.

At the present moment there are three Commonwealth Institutes : the Commonwealth Institute of Entomology at the British Museum (Natural History); the Commonwealth Mycological Institute at Kew (where I opened a new building in 1955); the Commonwealth Institute of Biological Control at the Science Building in Ottawa. There are ten Commonwealth Agricultural Bureaux dealing with the following subjects : animal breeding and genetics at Edinburgh; animal health at Weybridge; animal nutrition at Aberdeen; dairy science and technology at Reading (which I visited in 1954); forestry at Oxford; helminthology at St. Albans; horticulture and plantation crops at East Malling (which I visited in 1957) ; pastures and field crops at Hurley (which I visited in 1958) ; plant breeding and genetics at Cambridge; soils at Rothamsted (which I visited in 1954).

Each Institute or Bureau is attached to an institute or laboratory or university department doing active work in that particular science.

A similar but separate undertaking is the Commonwealth Geological Liaison Office, which has been conducting a survey of the mineral resources of the Commonwealth for the past six years. Sixty-five reports have been issued, and the Office has now started to review the position of each of the minerals for the second time.

These organizations are probably the most practical and scientifically useful co-operative under. takings in the Commonwealth to-day. However, that is not the end of the story. At the 1930 Imperial Conference two committees were formed to go into the subject of industrial and fundamental standards. This resulted in the Standards bodies of the Commonwealth countries maintaining regular and systematic consultations, and in 1946 they met in conference in London and again in 1957 in Delhi. There is every reason to believe that they will go on meeting in future because their work has been most rewarding and is proving very valuable to science and industry as well as to Commonwealth trade.

The Second World War inspired the formation of the British Commonwealth Scientific Offices in London and Washington. In them work the Scientific Liaison Officers attached to the High Commissioners' or Ambassadors' staffs. They run themselves and a great many other things besides, and they are without any doubt the most lively force in Commonwealth scientific co-operation at this moment.

I must refer to five more conferences which between them have stimulated a new wave of thought and 
activity on this subject of scientific co-operation. In $\mathbf{1 9 4 6}$ the Royal Society in London invited Commonwealth scientists to a conference in which they could speak as individual scientists. Immediately following this conference the Commonwealth Governments organized an official science conference where matters arising out of the Royal Society meetings could be discussed and official action taken. The reports of these two conferences make fascinating reading. First, because of the very obvious harmony and friendly spirit which existed throughout the discussions and, secondly, because of the immense scope of the diseussions, which touched every possible aspect of Commonwealth scientific co-operation.

The main topics of the discussions were: agricultural science ; medical science; nutrition and special problems of the Commonwealth; mapping and exploration by air; scientific information services in the Commonwealth ; interchange of scientists ; co-operation with international scientific organizations ; standards measurement; interchange of scientific material; land utilization and conservation; mineral resources of the Commonwealth; natural products and chemical industries which might use them; need for fundamental research; coordination of scientific work in Africa.

This last problem was considered at a special conference in London in 1949 and in Paris in 1950, and, as a result, the Commission for Technical Co-operation in Africa South of the Sahara, known as C.C.T.A., was formed. The members are: Belgium, the Federation of Rhodesia and Nyasaland, France, Portugal, the Union of South Africa and the United Kingdom. The Commission, among other things, convenes technical conferences, administers the Inter-African bureaux on various subjects, administers the Inter-African Research Fund and has established a number of advisory committees in various fields.

The third important conference was the Royal Society Scientific Information Conference of 1948 which, as its name implies, dealt with the problems of the collection, reproduction, abstraction and distribution of scientific information, particularly within the Commonwealth. This was, in fact, one of the first specialist conferences which had been recommended by the Royal Society meeting of 1946. The Conference suggested the formation of a Standing Committee on Information Services in order to "provide machinery for the interchange and coordination of ideas and information" which are emerging from the British Commonwealth as a result of the Conference.

The fourth Conference which is of particular interest was the British Commonwealth Scientific Conference held in Australia in 1952. I say particular interest because it was the first of this series of conferences attended by representatives from Pakistan and Ceylon. As to the business of the Conference I would like to quote a few sentences from the report : "The Conference felt that . . . the day to day contact of the liaison officers provided an effective system of collaboration which necessitated only occasional meetings of the heads of the official scientific organizations" and, later, "In addition to discussing how best to maintain collaboration the Conference dealt with a wide range of questions, including the application of the results of scientific research, the development of information services, the movement of scientists within the Commonwealth, the relations of the constituent organizations with inter- national bodies concerned with science or its application and the provision of technical man-power to assist underdeveloped countries". Again, "It was agreed as particularly important that developments should be watched in the following subjects : industrial microbiology, research in . . . the utilization of low-grade-ores, research on the utilization of solar energy by both physical and biological means, infertility of ruminant animals, agricultural engineering". In addition, it discussed the organization of national research bodies.

The Conference was opened by Mr. Menzies, the Prime Minister of Australia, with a most eloquent, appeal that the results of scientific research should find their way as quickly as possible into the hands of those who need to have the results.

The fifth Conference was the outcome of the Commonwealth Prime Ministers' meeting in 1957. They recommended an informal meeting of Commonwealth scientists to discuss the use of nuclear energy for civil purposes. The meeting was held during September 15-20, 1958, and every Commonwealth country except Malaya was represented. Not all the delegates were nuclear scientists because the main intention of the Conference was to develop a sense of Commonwealth partnership and inter-reliance in the development and application of nuclear energy. For example, although radioisotopes are produced by nuclear science, they can be used by many other interests-medical, biological, agricultural and industrial.

In the course of their five-day meeting the Commonwealth scientists did a bit of travelling and visited Harwell, the nuclear power station building at Bradwell, Calder Hall and Dounreay. They had one non-scientific interlude when the whole party, numbering about thirty-five delegates, came to lunch with The Queen and myself at Balmoral, and I was delighted to find Dr. Nazir Ahmad and Dr. Ghani among the party.

The latest of this series of conferences was held when the British Commonwealth Scientific Committee met in Canada in August 1958. At this meeting Ghana and Malaya took their places for the first time. The meeting decided to abolish the fullscale scientific conferences and substitute regular meetings of the British Commonwealth Scientific Committee consisting of the heads of the national research organizations of the Commonwealth countries. The Committee has decided to meet again in London. in 1960 .

\section{The Colombo Plan}

All these conferences have given point and direction to scientific co-operation, but no discussion on this subject would be complete without a reference to the Colombo Plan, particularly the technical cooperation scheme. The Plan was the outcome of a meeting of the Commonwealth Foreign Ministers at Colombo in 1950. The main part of the Plan deals, of course, with economic matters; but under the technical co-operation scheme there is a very considerable movement of students and experts in scientific and technological subjects between Commonwealth countries as well as between other south-east Asia countries and the United States. In the past eight years nearly 7,000 trainees and students have received instruction and just over 1,000 experts have been exchanged between the nineteen countries taking part-eleven of them Commonwealth. Of these, only three have not yet received any help and only five have so far been unable to offer any help. 
That, I think, is ample proof that this is a real co-operative effort.

Just as an illustration, it may interest you to know that, for example, Pakistan has received help from Australia, New Zealand, Canada and the United Kingdom, and has, in her turn, helped Burma, Japan, Malaya, the Philippines and Ceylon.

There are, of course, many schemes being developed under the Colombo Plan in Pakistan; but I am particularly interested in the Warsak hydro-electric and irrigation scheme because I hope to see how it is getting on in a few days time. It seems to be an excellent example of Commonwealth co-operation, as Canada is providing considerable technical assistance and is footing more than half the bill of 60 million dollars.

\section{The British Association}

Although, strictly speaking, the British Association is not primarily concerned with scientific co-operation within the Commonwealth, it has played quite an interesting part in the development of science and scientific institutions in Commonwealth countries. As the representative of the British Association at this meeting, I hope you will forgive me if I say a fow words about its contribution. The fact is that as early as 1884 the British Association held its annual meeting for the first time out of the United Kingdom, in Montreal ; in 1897 it went to Toronto, in 1905 it went to South Africa, in 1909 it was back in Canada at Winnipeg, and in 1914 it went to Australia. Since then it has been to Toronto again in 1924 and South Africa in 1929. In each case the report makes it quite clear that the personal contacts which were made at those meetings were considered highly valuable, while the suggestions made by the different sections about research projects were almost invariably put into effect. It was not a one-way business either. Visitors to the 1897 Toronto meeting were greatly impressed by the agricultural experimental stations established in Canada and it was recommended that the Council should approach the Home Government with a view to their imitation in Britain.

Modesty forbids me to suggest that any other Association for the Advancement of Science owes anything to the British Association, but they all have one pleasant feature in common. Members of any Association within the Commonwealth are welcome at any Association's meeting and every Association makes a point of inviting a delegation from other Associations to its meetings, and that is why $\mathrm{I}$ am here to-day.

\section{Movement of Scientists within the Commonwealth}

That, then, is a very general summary of the history and machinery of scientific co-operation within the Commonwealth; but there are, in fact, many other, perhaps more isolated, instances where the fact of the existence of the Commonwealth has affected the course of science.

Perhaps the most convincing example I can choose is the case of Lord Rutherford. Born in New Zealand in 1871, he went to Cambridge as an 1851 Exhibitioner, and from there he went to MeGill University in Canada as professor of physics, where he became famous for his brilliant work on radioactivity. In 1907 he moved to Manchester, where he developed his nuclear theory of the atom and accomplished the first artificial transmutation of matter by bombard- ment with particles. Returning to Cambridge in 1919 as Cavendish professor, he saw his prediction of the existence of the neutron realized by Chadwick.

Two others are of particular interest. Sir Ronald Ross was born in India in 1857 and later trained as a doctor in England. Fired by the vision of Patrick Manson, he returned to India determined to find out the cause of malaria. Within three years he pinned it down to the Anopheles mosquito and thus paved the way for the control of one of the worst scourges of mankind.

In a different field Sir Claude Inglis is another example. Trained at Dublin, he went to Sind Irrigation in 1906, and thirteen years later he established the first large-scale hydraulic model station in the world at Poona. In 1945 he returned to England to design and direct the Hydraulics Research Station at Wallingford, and he is now engaged on the Karna. fuli scheme for Pakistan.

There is, of course, an excellent example much nearer home, as the University of Lahore recently discovered when they lost Prof. A. Salam to the Imperial College of Science and Technology, London. However, the main thing is that his work on elementary particles will continue to be available to Commonwealth and world science wherever he works in the free world.

This freedom of movement, and the fact that most scientists within the Commonwealth use the same language, are conditions which we should exploit to the greatest extent for the benefit of scientists and through them of science and, ultimately, the people of the whole world.

It has long been recognized that this ability to move about freely within the Commonwealth is a unique advantage, and all the conferences of scientific co-operation have stressed the need for a greater movement of scientists between one country and another.

I was particularly interested to discover that this problem was first tackled as long ago as 1890 by the Commissioners of the Great Exhibition of 1851. In the regulations for their Science Research Scholarships it says : "The Scholarships are 'post-graduate', and are intended to enable selected students of overseas Universities who have already completed a full University course and given evidence of capacity for scientific investigation to devote themselves for two years to research work under conditions most likely to equip them for practical service in the scientific life of the Commonwealth". The Scholarships are tenable anywhere except in the country in which the student has received his scientific education. This scheme was the first of its kind and set the pattern for subsequent awards from other organizations. In 1958 the Commissioners made twenty-five awards.

I am afraid it is not a simple matter to find out exactly how many Commonwealth scientists are in fact studying or working in other Commonwealth countries under some kind of assisted exchange or seholarship scheme. The difficulty arises because the schemes are many and various and are operated by every kind of trust and benefaction.

So far as the United Kingdom is concerned, there are more than 500 schemes in operation designed to help people to study and work in that country, and some 124 to send people out of the United Kingdom. Apart from the 1851 Exhibition Scholarships, the Royal Society and the Nuffield Foundation run a bursaries scheme, and the British Council runs a universities exchange scheme. 
The same sort of thing is happening outside the United Kingdom. For example, the National Research Council of Canada offers post-doctorate Fellowships, and, since 1948 , some 574 research workers from other Commonwealth countries have worked in Canada, and, at the same time, about 40 Canadians each year are enabled to work in other countries. Under the Colombo Plan, Australia has taken 2,286 students from South-east Asia between 1951 and 1958 at a cost of $£ 3$ million.

Up to thirty years ago the Commonwealth and Colonial Empire looked to the United Kingdom as the scientific centre and no one spent much money on scientific research. However, in the past twenty years alone Government expenditure on research throughout the Commonwealth has risen by an estimated factor of fifteen.

\section{Original Scientific Work in Commonwealth Countries}

Statistics are well known to be misleading when handled by amateurs; even experts can make them do strange things, and in any event numbers in science give no clue to quality. Let me just remind you of some of the original scientific work carried out in Commonwealth countries other than the United Kingdom. It is an interesting fact that no less than forty-two Nobel Awards have been won by Commonwealth scientists. But, to be more specific, in 1921 Sir Frederick Banting, working with McLeod and Best in Canada, isolated insulin. Sir Macfarlane Burnet in Australia has immensely advanced our knowledge of viruses and their diseases. South African workers have recently developed the tellurometer, which measures base lines for surveying by radar in a fraction of the time needed by conventional methods. Also in South Africa, Sir Arnold Theiler and P. J. du Toit discovered that lack of phosphorus in the soil was the cause of widespread botulism in cattle. Workers in Australia and New Zealand followed this with their discovery of the importance of trace elements in plant and animal health. Edwards in India developed a vaccine against rinderpest. Scientists in Canada have been fighting a long and unremitting battle against black rust in wheat and here in Pakistan research is active in this field as well as in mechanical rice cultivation and in cotton breeding, all of which has an international reputation. The names of Venkata Raman in physics and Ramanujan in mathematics are respected and admired throughout the world.

All this convinces me that the whole Commonwealth would benefit greatly from a larger movement of scientists either as students, research workers, scientific expedition members or as teachers. The important thing, therefore, is to devise practical and simple machinery to encourage this movement to take place.

The present pattern of scientific co-operation within the Commonwealth can be divided into five parts : (1) the regular discussion of general scientific problems and of problems particular to the Commonwealth; (2) the discussion of the problems of the administration of science and research; (3) the regular exehange of scientific information; (4) the movement of scientists; (5) technical help and advice.

(1) and (2) are achieved by regular conferences and contacts between the official research organizations. (3) is achieved by the British Commonwealth Scientific
Offices and the Commonwealth Agricultural Bureaux. (4) is achieved by bursaries, scholarships, lectureships and various other schemes of assisted exchange, while the Colombo Plan has encouraged tremendous progress in (4) and (5).

$I$ ought to add at this point that nothing $I$ have said refers to the personal and informal contacts which exist between individual scientists within the Commonwealth. The total of this informal cooperation is probably greater than anything organized through more or less official channels, but of course there are no statistics.

\section{Suggestions to improve Scientific Co-operation}

So far I have only dealt with facts. Now I am going to be rather more rash and put forward some suggestions to increase the amount of co-operation between Commonwealth countries. I will not go so far as to say that these suggestions are possible in practice. I would merely say that they are desirable.

I would like to see the system of the Commonwealth Agricultural Bureaux extended to other sciences and set up in whichever country has the greatest interest in the particular subject. Secondly, I would like to see the system of the British Commonwealth Scientific Offices extended to other Commonwealth countries; this may be a bit premature but, as it is, many Commonwealth countries are doing original research in subjects which are of great interest to others. Thirdly, it would make a wonderful story if countries could pool their resources and plan together the attack on common problems. I say deliberately that it would make a nice story because I do not think scientists or anyone else work that way. It always seems to me that individual laboratories like to attack problems in their own way even though they are quite willing, indeed eager, to discuss the results with anyone who is interested. Therefore, I believe the most we can hope for is a broad agreement about which problems appear to be most important for the time being, followed by a frank exchange of the results of research.

Next I would like to see joint action on scientific problems which affect Commonwealth industry, commerce and trade. Although more than half the research associations in the United Kingdom have Commonwealth members and the flow of technical information is not impeded in any way, except if the industries are in direct competition, I am convinced that wider membership of research associations and more co-operation between research associations in all the Commonwealth countries is both possible and desirable.

However, I am not blind to the complications. Scientists very naturally imagine that anything new which they discover and which seems to them important must be obviously immediately useful to industry. In fact, the most shattering scientific advances may not be of any practical use for many years while some trifling nonsense produced almost by mistake in a laboratory working on, for example, hydraulies may turn out to be vitally valuable to the boot and shoe industry. Furthermore, even if it can be proved quite easily that a particular discovery will revolutionize cotton farming, it does not necessarily follow that cotton farmers will accept and apply the discovery just like that.

For example, I understand that the Laboratories of the Pakistan Council for Industrial Research have, in fact, completed sixteen processes making use of 


\section{№. 4659 February 14, $1959 \quad$ N A T U R E}

indigenous materials which are ready for exploitation by industrialists. Some have already been taken up, but I would not be surprised to hear the chairman of that Council say that "you can lead an industrialist to the waters of science but you can't make him drink".

There is only one way to ensure the early application of scientific research. It is essential that industry and all other potential users of scientific production should be as closely associated with the research organization as possible at all times. Industries and farmers must be encouraged to make direct use of research facilities by asking questions, and they must also be made to feel a personal interest in the research activities by being asked to take part in experiments and developments.

The rules of human nature are not really very complex. If somebody offers you advice, the chances are you will tell him to mind his own business; if, on the other hand, he asks you for your advice and help, you are probably rather flattered.

The key to the problem of the application of scientific discovery is the closest collaboration between the research establishments and industry.

\section{Benefits of Commonwealth Scientific Comoperation}

So far I have assumed that there is some advantage to be gained from Commonwealth co-operation in science. I have assumed that in the long run the ordinary people of the countries of the Commonwealth will be better off if we make the fullest use of the freedom of movement of scientists and scientific ideas and a common scientific language. However, if this is true, if this business of co-operation is really and practically worth while, there must be some concrete examples which provide conclusive proof. Naturally, I would not have raised this point unless I had that proof.

I think we all agree that where it is possible scientific co-operation should be truly international, and enterprises like the International Geophysical Year, the Organization for European Economic Co-operation, and, on a smaller scale, the Commission for Technical Co-operation in Africa South of the Sahara, and the Colombo Plan show that this can happen. Nevertheless, in spite of the wide differences between the circumstances of the Commonwealth countries, the fact that they have similar institutions often makes it possible to organize co-operation on a Commonwealth scale when it is not possible internationally. For example, international efforts were made for years, without success, to organize the preparation of comprehensive catalogues of cultures of micro-organisms. Preparation of such catalogues within the Commonwealth was organized at a meeting lasting three days.

The Commonwealth operates an "Index of Translations", so that a scientific paper translated anywhere in the Commonwealth is available to any research worker. The Organization for European Economic Co-operation has so far failed in its efforts to organize a similar index.

To add weight to the argument $I$ have chosen two examples which particularly concern Pakistan. Agriculture is, and must remain, the most important industry of Pakistan. For many years the soil will remain its main source of wealth. Anything therefore which advances the art and science of agriculture is vital.
After the First World War investigations were started by meteorologists in England to investigate the behaviour of the layer of air within $100 \mathrm{ft}$. of the ground about which practically nothing was known. The immediate purpose of this work was military - to study the rate of evaporation from the ground of poisonous gases and the travel of gas and smoke clouds. This work has been continued at Cambridge, and from measurements of the humidity and wind velocity at different heights an electronic computer can calculate the mean water-loss of crops hour by hour. It is then possible to estimate the water consumption of farm crops by physical measurements of the micro-climate. It is a bit early to say what the practical application is going to be ; but it shows how scientific research planned for one object in one part of the Commonwealth can produce unexpected techniques and results for other purposes in other places. I hope this matter will be of particular interest to the president of the Pakistan Association for the Advancement of Science, whose work on soil science is well known and who now controls agricultural development in East Pakistan.

The second example concerns a specific investigation. A model investigation is now in progress at the Wallingford Hydraulics Research Station in England to determine the causes of the changes in the bed of the mouth of the Karnafuli River in East Pakistan so that the conditions at the port of Chittagong can be improved and stabilized. This particular piece of work is being done under the Colombo Plan.

In neither case has there been any question of attempting to gain either economic or political advantage. There has been no question of prestige or personal glory. These two cases are typical of hundreds which are in the pipe-lines of Commonwealth co-operation in science, pipe-lines which should be made to carry information and ideas in both directions between all members of the Commonwealth of Nations.

I do not really believe that anyone can seriously doubt that science devoted to fundamental research and the application of natural knowledge to civil and peaceful ends is capable of bestowing the most wonderful benefits upon mankind. In our own time it has brought about a period of almost headlong industrial and therefore economic expansion. I need scarcely emphasize the profound effect which science has had upon medicine and agriculture. (Although the cynic might say that scienee has simply made it possible for agriculture just to keep pace with the growing demand for food which is a direct result of the effects of improved medical practice.) All the same, there is no use denying that the developments brought about by scientific research have produced a whole host of new problems; problems which can only be alleviated by humane and thoughtful administration; problems which scientists, in company with all other professional groups, must face and overcome as ordinary thinking human beings.

By far the most harrowing problem is the use of science for destructive and warlike purposes. Everyone deplores it ; but there is obviously no immediate solution. However, I firmly believe that if we can go on building on this foundation of peaceful co-operation between Commonwealth countries in all spheres of activity, we shall be doing much more than simply helping ourselves; we shall eventually have a structure which will give hope and confidence to all the men and nations of the world and then science at last will be freed for ever from the grim necessity to invent weapons of destruction. 